\title{
Optimization Design of Building Integrated Photovoltaic System with LOLP Algorithm
}

\author{
Chunlei Zhao ${ }^{\mathrm{a}}$, Liang Guo ${ }^{\mathrm{b}}$, Xu Zhang ${ }^{\mathrm{c}}$, and Yaodan $\mathrm{Chi}^{\mathrm{b}, *}$ \\ ${ }^{a}$ Creative Centre for ArtSciArch, Jilin Provincial Key Laboratory of Architectural Electricity and Comprehensive Energy Saving Jilin Jianzhu University, \\ Changchun, 130118, China \\ ${ }^{b}$ School of Electrical and Electronic Information Engineering, Jilin Provincial Key Laboratory of Architectural Electricity and Comprehensive Energy \\ Saving, Jilin Jianzhu University, Changchun, 130118, China \\ ${ }^{c}$ Jilin Provincial Key Laboratory of Architectural Electricity and Comprehensive Energy Saving, Jilin Jianzhu University, Changchun, 130118, China
}

\begin{abstract}
With the development of science and technology, the research and application of building-integrated photovoltaic (BIPV) has become a hotspot. In this paper, we present a creative design scheme using an optimization algorithm called LOLP algorithm of a set of independent photovoltaic (PV) systems in remote areas of Jilin Province. Through the aiding design of the professional photovoltaic system PVsyst software, we discuss the improvements after using this creative design method in the software.
\end{abstract}

Keywords: photovoltaic system; optimization algorithm; PVsyst software

(Submitted on November 12, 2018; Revised on December 17, 2018; Accepted on January 15, 2019)

(C) 2019 Totem Publisher, Inc. All rights reserved.

\section{Introduction}

Currently, the rapid development of social economy is built on the basis of huge energy consumption, and building energy consumption is a major consumer in our society. With the decrease in non-renewable energy and the increasingly severe pollution of the environment, the exploitation and utilization of renewable energy becomes more and more necessary and meaningful. As an important renewable clean energy, solar energy has become a research hotspot because of its advantages, such as green environmental protection, extensive resources, and inexhaustible resources. There will be a far-reaching influence on building energy efficiency to make use of solar energy resources rationally by photovoltaic technology.

In this paper, we present an optimized design of a set of independent photovoltaic (PV) systems in remote areas of Jilin Province. Through the aiding design of the professional photovoltaic system PVsyst software, we discuss the improvements after using the LOLP operation design method in the software.

\section{Principle of PV Systems}

The solar photovoltaic power generation system is a system that converts solar energy into electrical energy by using solar cell modules and other auxiliary equipment, and BIPV technology is the integration of solar power generation (PV) products into building technology. Photovoltaic systems allow homeowners to generate electricity in a clean, reliable, and quiet way that can offset future electricity costs and decrease their dependence on the energy grid.

Photovoltaic systems are long-lasting (the first PV system ever installed in the USA - in 1954 - is still operating today). Most manufacturers warranty their products power output for a minimum of 20 years. However, most solar professionals agree that a system should last at least 25-30 years.

To achieve the sustainable development of energy and environment, many countries have made solar PV a new and

\footnotetext{
* Corresponding author.

E-mail address: 413945542@qq.com, 104952034@qq.com, 328765452@qq.com, 147670107@qq.com
} 
renewable energy in development of the energy industry all over the world. Many countries have large solar resources, numerous building roofs, and desert resources for small- and large-scale development of photovoltaic power generation. PV will play an important role in the world's future electricity supply.

A photovoltaic installation typically includes an array of photovoltaic modules or panels, an inverter, storage batteries (for stand-alone PV system), and interconnection wire. Most modules are rigid, but there are some flexible modules available, based on thin-film cells.

\subsection{Photovoltaic Modules}

There are three basic types of PV modules based on different cells: monocrystalline, polycrystalline, and thin-film. All modules work well, although monocrystalline cells often yield the greatest efficiencies. Thin-film technology typically costs less, and its efficiency is ever improving as the demand for solar panels grow. A growing variety of manufacturers and models are available in the market place today.

In the field of photovoltaics, a photovoltaic module or photovoltaic panel is a packaged interconnected assembly of photovoltaic cells, also known as solar cells. An installation of photovoltaic modules or panels is known as a photovoltaic array. Photovoltaic cells typically require protection from the environment. For cost and practicality reasons, a number of cells are connected electrically and packaged in a photovoltaic module, while a collection of these modules that are mechanically fastened together, wired, and designed to be a field-installable unit, sometimes with a glass covering and a frame and backing made of metal, plastic, or fiberglass, are known as a photovoltaic panel or simply solar panel.

\subsection{Inverter}

An inverter converts the direct current (DC) voltage of the PV modules to the two-phase or three-phase AC voltage of the public grid. According to the grid connection, the inverter can be divided into two categories: off grid inverter in standalone systems and grid-connected inverter in grid-connected systems [1-2].

\subsection{Storage Battery}

The storage battery is the energy storage equipment of photovoltaic systems and is related to the stability of photovoltaic power generation systems. When light is insufficient, or the load demand is greater than the power generated by the solar cell module, the battery releases the stored energy to meet the load capacity requirements.

\subsection{Performance of BIPV Systems}

Broadly speaking, the performance of the Building Integrated PV (BIPV) system includes two aspects. First, the aesthetic character of building components should be considered, that is to say, the expressive power of architectural art. This is mainly determined by the external color, texture, assembly and installation form of solar cell modules and other factors. Additionally, the power generation performance of the BIPV system is the core performance of the system. This is mainly determined by the following factors: geographical position and climatic factors, the orientation and inclination of the PV module, shadows, temperature, etc.

\section{Design Method of Stand-Alone Bipv Systems}

Stand-alone PV systems are mostly used in remote areas such as remote mountain areas, border posts, etc [3-5].

\subsection{Design Principles}

Designers should follow the following four design principles in designing BIPV systems [6-9].

First, principles of architectural aesthetics: As a part of the building, the whole system should meet people's requirements for architectural aesthetics. The position and area of the PV system in the building and the shape and color of the selected photovoltaic components should be in harmony with the overall style of the building.

Second, building function principle: The BIPV system should simultaneously satisfy the architectural functions such as protection, stress, heat insulation, waterproofing, lighting, and shading as the corresponding building components. 
Third, maximum power output principle: Because the power generation of the BIPV system is based on the area of the photovoltaic module, designers should choose the appropriate type of solar cells used in the limited space of the building and arrange the orientation and inclination of solar cells reasonably to maximize the power output of the BIPV system and reduce the time of the project cost recovery period.

Finally, principle of stability and maintainability: Buildings usually have decades or even hundreds of years of service life. At the same time, the life span of the BIPV system is generally 20-25 years. Thus, the BIPV system should be able to operate safely and steadily in its life cycle and avoid the failure and danger caused by equipment and installation as much as possible. Also, the solar cells and electrical equipment components used in the PV system should be standardized and generalized to facilitate the replacement and maintenance of equipment in the daily operation of the BIPV system.

\subsection{Introduction of LOLP Method}

The storage battery is an elementary part in the stand-alone PV system, because the power generated by the solar panels is not stable and will change with the climate condition and season. As a result, the storage battery is essential as a buffer. In the design process of stand-alone photovoltaic power generation systems, it is very important to choose the type and capacity of the battery. It can be said that the capacity of the battery plays a decisive role in the normal power supply of stand-alone photovoltaic power generation systems [11-13]. The system designer should anticipate the change of the solar radiation and optimize the combination of the solar panel and the storage battery capacity to meet the reliability of the power supply to the users [13-15]. The level of reliability is called loss of load probability (LOLP), and LOLP indicates that the system meets the level of load requirements. When LOLP $=1$, it means that the system cannot meet the load requirements, and when $L O L P=0$, it means that the system can fully meet the load requirements.

The basic formula of the LOLP method is as follows.

$$
\begin{aligned}
& A=E_{L} /\left(P O A_{o} \eta_{\text {in }} \eta_{\text {out }}\right) \\
& B=\left(E_{L} s\right) / \eta_{\text {out }}
\end{aligned}
$$

- $A-$ - Area of battery

- $B-$ Battery capacity

- $E_{L}$ - Load power

- $P O A_{O}$ - - The design value of the monthly average horizontal surface emission of the designed object

- $\eta_{\text {in }}$ - The efficiency from solar radiation to battery efficiency

- $\eta_{\text {out }}$ - The efficiency from battery to load

- $s$ - Power storage days

\section{Common Design Method}

\subsection{Basic Parameters}

The summer optimum design is used to obtain the best inclination angle of 30 degrees in summer, as shown in Figure 1 . The calculation method of monthly average solar radiation on the inclined plane is as follows.

$$
\bar{R}=D+\frac{\overline{H_{d}}}{2 \bar{H}}(1+\operatorname{Cos} \beta)+\frac{\rho}{2}(1-\operatorname{Cos} \beta)
$$

- $\bar{R}$ — The ratio of monthly average solar radiation on the inclined plane and monthly average solar radiation on the horizontal plane

- $\quad D$ - The monthly average diffuse irradiation on the horizontal plane

- $\overline{H_{d}}$ - The monthly average total irradiation on the horizontal plane

- $\beta$ - The tilting angle of the array

- $\rho-$ - Surface albedo, in general, take 0.2

We can calculate the result as $1751 \mathrm{kWh} / \mathrm{m} 2 /$ year. The peak sunshine of the inclined plane is 4.79 . 
Tilt 30 deg
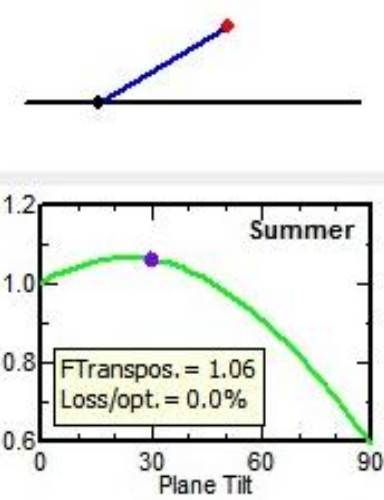

Figure 1. Summer program optimization best angle of 30 degrees
Azimuth 0 deg
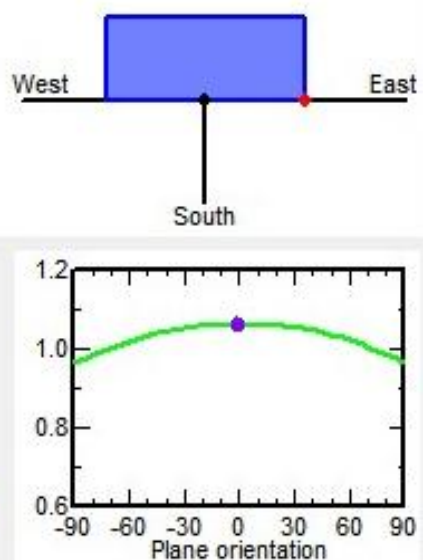

\subsection{Selection of Battery and Solar Panel Capacity}

Firstly, the DC voltage of the system should be determined. According to the design standards, there are several selections.

$12 \mathrm{~V}$ : For a small system for lamps and TVs. The maximum power is less than $300 \mathrm{~W}$, the corresponding current is $25 \mathrm{~A}$, and the inverter is less than $1 \mathrm{~kW}$.

24V: For medium-sized systems with small electrical appliances and refrigerators. The maximum power of the appliances is less than $1000 \mathrm{~W}$, the corresponding current is $42 \mathrm{~A}$, and the inverter is less than $5 \mathrm{~kW}$.

48V: For small systems in special industry and agriculture. The maximum power is less than $3000 \mathrm{~W}$, the corresponding current is $62 \mathrm{~A}$, and the inverter is less than $15 \mathrm{~kW}$.

Here, this system selects $24 \mathrm{~V}$.

Secondly, the battery capacity can be calculated with the following calculation.

$$
B_{C}=\frac{A \times Q_{1} \times N_{1} \times T_{0}}{C_{C} \times V}
$$

- $A-$ Safety factor, the value is 1.1-1.4

- $Q_{1}$-Daily power consumption, here we take $3.8 \mathrm{kWh}$

- $T_{0}$ - Temperature coefficient, generally, $>0{ }^{\circ} \mathrm{C}, 1$

From -10 to $0^{\circ} \mathrm{C}, 1.1 ;<10^{\circ} \mathrm{C}, 1.2$

- $C_{c}$ - Depth of discharge, here we take 0.8

- $N_{1}$ - The number of self-supporting days, here we take 4

- $V$ - Working voltage, here we take $24 \mathrm{~V}$

(Generally, there are three choices here: for a small system whose maximum power of the appliance is lower than $300 \mathrm{~W}$, take $12 \mathrm{~V}$; for a medium system whose maximum power of the appliance is lower than $1000 \mathrm{~W}$, take $24 \mathrm{~V}$; and for a system used in special industrial and agricultural, take 48V.)

It can be calculated that the result is $1045 \mathrm{Ah}$. We choose the storage battery with $12 \mathrm{~V}, 160 \mathrm{Ah}$, two-series and sevenparallel, and a capacity of $1120 \mathrm{Ah}$. 


\subsection{The Design of the Photovoltaic Array}

The PV module selects the following parameters: $200 \mathrm{Wp}$, working voltage $27 \mathrm{~V}$, and working current $7.6 \mathrm{~A}$.

$$
N_{s}=(V \times 1.43) \div V_{p p}
$$

- $N_{s}-$ - Series number of the PV module

- $V$ - Working voltage

- $V_{p p}$ - Peak voltage

$$
N_{p}=\frac{Q_{1} \times C_{Z}}{V \times H \times \eta_{1} \times \eta_{2} \times A}
$$

- $N_{p}$ - Parallel number of the PV module

- $C_{z}$ - Comprehensive coefficient, here we take 1.02

- $\eta_{1}$ - Inverter efficiency, here we take 0.9

- $\eta_{2}$ - Charging efficiency, here we take 0.8

- $Q_{1}$ - Daily power consumption

- $H$ - - Peak sun hours

- $A$ - Peak current

It can be calculated that the result of $N_{s}$ is $1, N_{p}$ is 6 , and the total power is $1200 \mathrm{~W}$.

\section{The Creative Design Part}

\subsection{The Creative Design Scheme}

PVsyst, a powerful software for photovoltaic systems, is designed to be used by architects, engineers, and researchers. It is also a very useful educative tool. It includes a detailed contextual help menu that explains the procedures and models that are used and offers a user-friendly approach with a guide to develop a project. PVsyst is able to import meteo data from many different sources, as well as personal data. PVsyst presents results in the form of a full report, specific graphs, and tables, and data can be exported for use in other software.

The simulation process is the following. First, we should set the parameter. The LOLP value is $5 \%$, and the selfsupporting days are 4 days. Second, we can get that the result is $200 \mathrm{Wp}$ component, one-series and four- parallel, and the nominal total power is $800 \mathrm{~W}$. The parameter of the battery is $12 \mathrm{~V} / 160 \mathrm{Ah}$, two-strings and five-parallel, and the capacity is 800Ah.

\subsection{The Effect of the Creative Design}

We will conduct a comparative analysis between the common method and the creative LOLP algorithm calculation through simulation by the PVsyst software.

First of all, the results of the formula calculation with the common method are shown in Figure 2. The PR, which refers to the operating efficiency of the system, is mainly below 50\%. As a contrast, the result using the LOLP algorithm optimization is much more reasonable, as shown in Figure 3.

Also, we can compare the data of the waste between the two design methods from Figures 4 and 5. We can observe and analyze the data of $\mathrm{Lu}$, which refers to the percentage of unused electrical energy and the power supply for users. Obviously, the design with the LOLP algorithm is much more reasonable and better.

In Tables 1 and 2, the parameters' meanings are as follows.

- EffBatE: Battery charge and discharge efficiency

- EffBatl: Battery current charge and discharge efficiency 
- MGss: Free electrolyte for single cell

- WeState: Current life status

- Wecycle: Cycle induced losses

- soc engd: Discharge depth at the end

- ubatt: Voltage

As can be seen from Tables 1 and 2, manual calculation results show that the design value is too large, the average discharge depth is above $80 \%$, the system operation rate is low, and the battery is in a shallow cycle state for most of the time. It can also be seen that the supply rate of the stand-alone photovoltaic power generation system was too high in the winter, and the loss occurred in July and August, because the dip angle was positioned the best in the summer. Therefore, this is the best scheme of LOLP at $5 \%$.

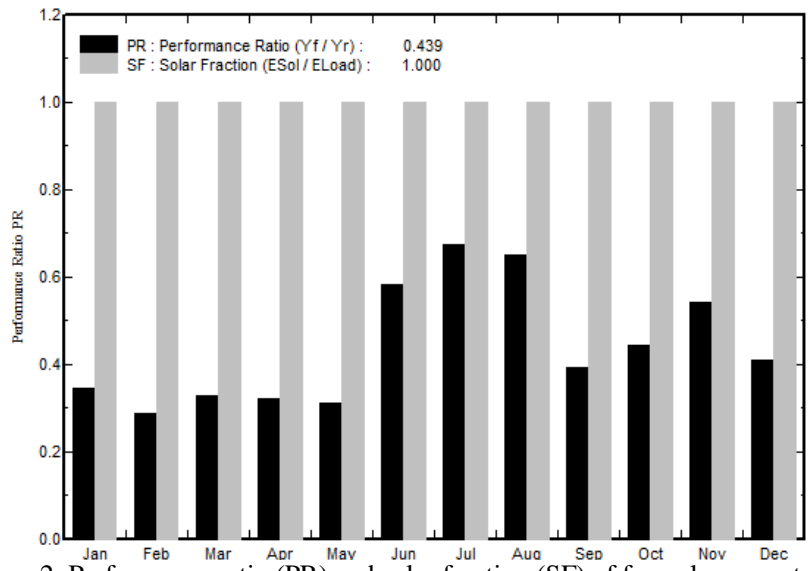

Figure 2. Performance ratio (PR) and solar fraction (SF) of formula computation

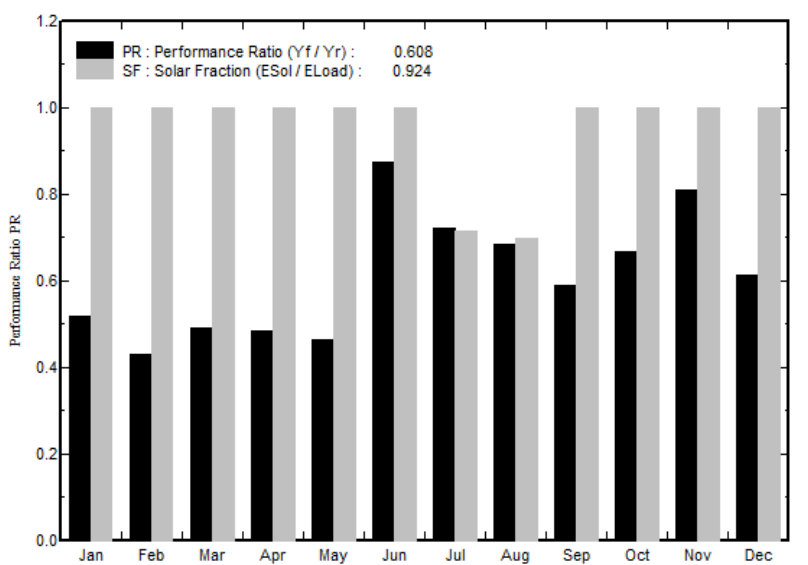

Figure 3. Performance ratio (PR) and solar fraction (SF) of LOLP algorithm

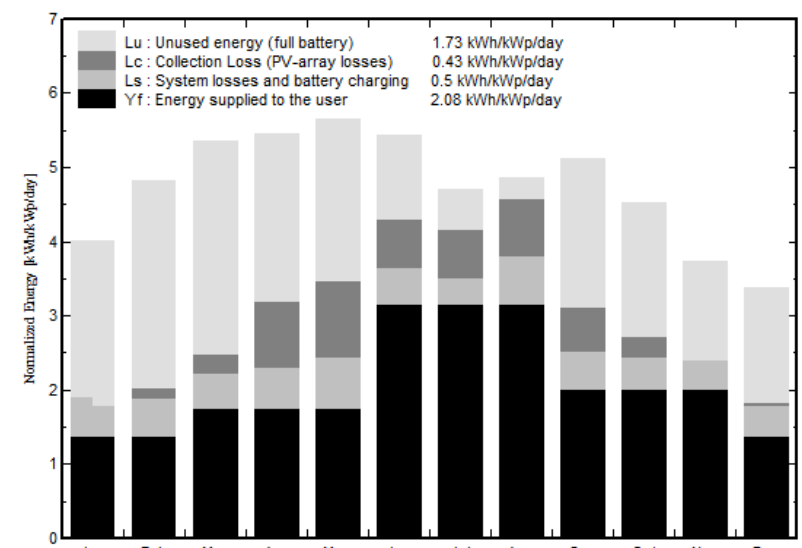

Figure 4. Normalized productions of formula computation (nominal power $1200 \mathrm{Wp}$ ) 


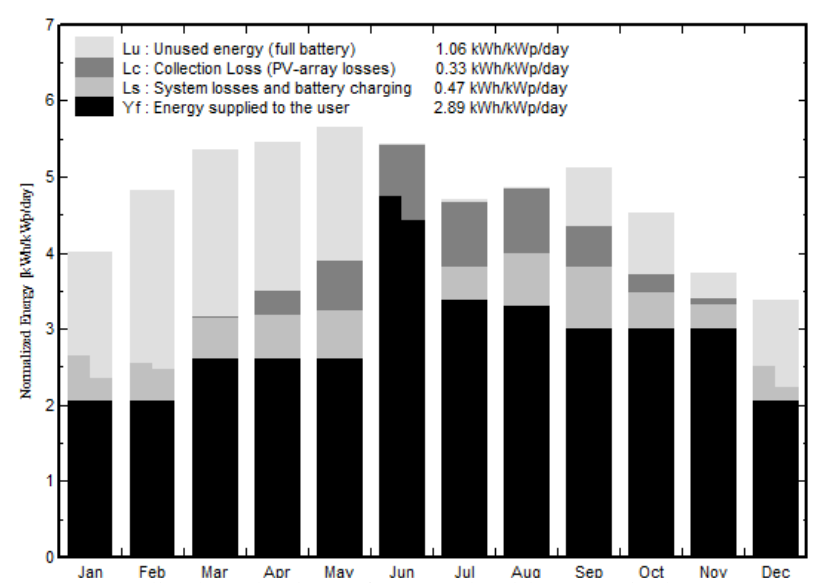

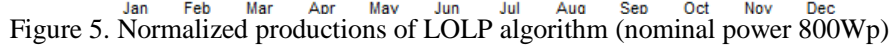

Table 1. Battery run simulation of formula computation

\begin{tabular}{|c|c|c|c|c|c|c|c|c|}
\hline & $\begin{array}{c}\text { U Batt } \\
\text { V }\end{array}$ & SOCmean & SOC End & $\begin{array}{c}\text { WeCycle } \\
\%\end{array}$ & $\begin{array}{c}\text { WeState } \\
\%\end{array}$ & $\begin{array}{c}\text { MGass } \\
\text { liter }\end{array}$ & $\begin{array}{c}\text { EffBatl } \\
\%\end{array}$ & $\begin{array}{c}\text { EffBatE } \\
\%\end{array}$ \\
\hline January & 27.8 & 0.880 & 0.862 & 0.22 & 99.7 & 0.079 & 78.4 & 77.6 \\
February & 27.5 & 0.903 & 0.892 & 0.18 & 99.5 & 0.096 & 84.9 & 80.8 \\
March & 27.0 & 0.902 & 0.885 & 0.21 & 99.2 & 0.114 & 86.2 & 84.2 \\
April & 26.3 & 0.909 & 0.894 & 0.17 & 98.7 & 0.134 & 85.1 & 82.1 \\
May & 25.9 & 0.914 & 0.900 & 0.17 & 98.0 & 0.160 & 83.6 & 80.5 \\
June & 25.2 & 0.806 & 0.518 & 0.20 & 96.9 & 0.068 & 93.3 & 106.7 \\
July & 24.5 & 0.589 & 0.258 & 0.22 & 95.7 & 0.009 & 96.6 & 105.1 \\
August & 24.6 & 0.578 & 0.826 & 0.22 & 94.7 & 0.010 & 94.2 & 80.0 \\
September & 25.9 & 0.901 & 0.883 & 0.18 & 94.0 & 0.129 & 87.0 & 82.2 \\
October & 26.3 & 0.876 & 0.877 & 0.19 & 93.5 & 0.094 & 89.7 & 87.9 \\
November & 27.0 & 0.850 & 0.818 & 0.21 & 93.2 & 0.073 & 89.2 & 90.7 \\
December & 27.6 & 0.873 & 0.878 & 0.21 & 93.0 & 0.085 & 87.6 & 82.3 \\
\hline Year & 26.3 & 0.831 & 0.878 & 2.39 & 93.0 & 1.051 & 88.8 & 87.2 \\
\hline
\end{tabular}

Table 2. Battery run simulation of LOLP algorithm

\begin{tabular}{|c|c|c|c|c|c|c|c|c|}
\hline & $\begin{array}{c}\text { U Batt } \\
\text { V }\end{array}$ & SOCmean & SOC End & $\begin{array}{c}\text { WeCycle } \\
\%\end{array}$ & $\begin{array}{c}\text { WeState } \\
\%\end{array}$ & $\begin{array}{c}\text { MGass } \\
\text { liter }\end{array}$ & $\begin{array}{c}\text { EffBatl } \\
\%\end{array}$ & $\begin{array}{c}\text { EffBatE } \\
\%\end{array}$ \\
\hline January & 27.8 & 0.897 & 0.883 & 0.17 & 99.8 & 0.118 & 72.6 & 71.6 \\
February & 27.6 & 0.919 & 0.908 & 0.15 & 99.6 & 0.198 & 76.9 & 72.0 \\
March & 27.0 & 0.918 & 0.902 & 0.16 & 99.3 & 0.189 & 81.2 & 78.5 \\
April & 26.4 & 0.926 & 0.908 & 0.13 & 98.8 & 0.236 & 78.7 & 75.0 \\
May & 26.1 & 0.934 & 0.931 & 0.14 & 98.1 & 0.327 & 74.9 & 69.8 \\
June & 25.5 & 0.897 & 0.807 & 0.18 & 97.1 & 0.211 & 85.7 & 88.5 \\
July & 25.1 & 0.832 & 0.671 & 0.16 & 95.9 & 0.131 & 89.6 & 94.2 \\
August & 25.3 & 0.835 & 0.880 & 0.16 & 94.9 & 0.121 & 90.4 & 82.3 \\
September & 25.9 & 0.918 & 0.901 & 0.14 & 94.2 & 0.193 & 83.2 & 79.1 \\
October & 26.4 & 0.905 & 0.897 & 0.15 & 93.8 & 0.150 & 86.0 & 83.5 \\
November & 27.1 & 0.897 & 0.874 & 0.17 & 93.5 & 0.135 & 85.6 & 84.8 \\
December & 27.7 & 0.906 & 0.896 & 0.16 & 93.3 & 0.148 & 81.9 & 77.7 \\
\hline Year & 26.5 & 0.898 & 0.896 & 1.89 & 93.3 & 2.157 & 83.0 & 80.5 \\
\hline
\end{tabular}

\subsection{The Analysis of the Creative Design}

Firstly, in this design, photovoltaic technology and buildings are combined to achieve energy-saving purposes technically. 
More importantly, it makes building saving technology step to active energy-saving from passive energy-saving. Through the integration of solar power generation system and building components, it can not only assume the building function of the building components in the building, but also perform photoelectric conversion to provide power for the system load [16-17]. BIPV buildings can be regarded as a derivative of photovoltaic power plants. Because the solar radiation energy per unit area is very small, photovoltaic power plants need to occupy a large area to obtain solar energy. When photovoltaic systems are combined with buildings, no additional ground space is required. Currently, BIPV has been widely used in the world and has achieved many successful experiences. It can effectively reduce building temperature, save energy, reduce emissions, and alleviate air pollution, thus realizing the organic combination of smart city, ecological city, and low-carbon city.

Secondly, the traditional architectural aesthetics have been given new life from the optimized design of the photovoltaic system. The combination of photovoltaic and architecture gives new life to architectural design from the aesthetic point of view. As we know, architecture is a landscape that satisfies viewers visually. Apparently, the integration of PV system and architecture makes the appearance of the building more attractive. Through the design and application of the photovoltaic system, the photovoltaic system can be perfectly integrated with the building. The buildings built with photovoltaic systems are like carefully carved works of art, showing a new beauty of photovoltaic. The use of photovoltaic components in buildings not only makes good use of solar energy and saves energy greatly in buildings, but also enriches the structural forms of facades and roofs of buildings.

For designers, the building-integrated photovoltaic system should not only maintain the integrity and unity of the building, but also highlight the unity of vision and art. Designers of photovoltaic buildings should reorganize the form and order of buildings on the basis of not destroying the formal beauty of the original buildings and give full play to the visual characteristics and formal beauty of photovoltaic materials. Then, the buildings can be combined with the form and characteristics of photovoltaic materials organically. In this design pattern, it can achieve harmony and unity in aesthetics, thereby increasing the aesthetical value of buildings.

Thirdly, BIPV design should be based on the basic principle of not damaging and affecting the effect, structural safety, function, and service life of the building. Any BIPV design that causes damage and harmful effects on the building itself is unqualified design. Therefore, it is essential that the design should be scientific and reasonable. In this paper, we creatively use an optimization design method to realize the simulation design of the photovoltaic building system. Through our optimization design, it would be helpful for photovoltaic architects to obtain more scientific and reasonable parameters of the PV systems so as to achieve a more reliable and reasonable architectural design. Through the simulation and comparative analysis of the two sets of schemes, it can be concluded that the optimization design by the LOLP algorithm can achieve more accurate capacity matching. In this way, we can reduce the input cost and avoid waste of resources due to excessive use of equipment.

All in all, there is no doubt that the BIPV system is not a simple superposition of the photovoltaic power generation system and buildings. From the beginning of architectural design, all the contents of solar energy systems should be considered as an indispensable design element of buildings, ingeniously incorporating all parts of solar energy systems into buildings and becoming an indispensable part of the buildings. Through the optimized design creative application of the PV systems in the buildings, both the practical and aesthetical value of architecture can be realized.

\section{Conclusions}

BIPV technology integrates architecture, technology, and aesthetics. It creates a new concept of architectural design and opens up a new field of architectural, electrical design. As an advanced high-tech system, the BIPV system plays a key role in building low-carbon, energy-saving, and environmental protection green buildings.

In this design, we provide a creative scheme to apply in the stand-alone photovoltaic power generation system. According to the contrast of the results of the traditional scheme and our creative scheme, which is the LOLP algorithm in PVsyst software, it can be concluded that the matching capacity of PV modules and batteries calculated by the formula is too large, and the matching capacity of PV modules and batteries calculated by the LOLP algorithm is more reasonable. The creative design can reduce the cost of investment and avoid the waste of resources caused by excessive use of equipment.

\section{Acknowledgments}

This work was supported by the Science and Technology Planning Project (No. 20160204069GX, 20170101111JC, and JJKH20170243KJ). 


\section{References}

1. V. A. Ani, "Design of a Stand-Alone Photovoltaic Model for Home Lightings and Clean Environment," Frontiers in Energy Research, Vol. 3, 2016

2. Y. P. Xiao, "Optimal Design of Stand Alone Photovoltaic Power Generation System based on PVsyst," Chinese Journal of Power Sources, Vol. 7, 2016

3. L. Gao, Q. Hao, Y. Zhu, et al., "Research and Design on Household Stand-Alone Photovoltaic Power Generation System," Journal of Henan Agricultural University, Vol. 1, 2015

4. J. Song, Y. X. Xie, W. L. Wang, et al., "Design and Simulation of Solar Photovoltaic Parking Shed based on PVsyst," Electronics Quality, Vol. 8, 2017

5. W. Zhu and L. Sun, "The Simulation Design of Household Photovoltaic System based on PVSYST," Journal of Changzhou Vocational College of Information Technology, Vol. 4, 2015

6. D. Kang and T. T. Jing, "Design of Household Photovoltaic Power Generation System based on ARM," Chinese Journal of Power Sources, Vol. 8, 2016

7. F. Liu, L. I. Yan, X. Z. Zhang, et al., "Design of Stand-Alone Photovoltaic Generation System based on DSP," Chinese Journal of Power Sources, 2013

8. H. C. Chen, "Optimum Capacity Determination of Stand-Alone Hybrid Generation System Considering Cost and Reliability," Applied Energy, Vol. 103, No. 1, pp. 155-164, 2013

9. A. González, J. R. Riba, and A. Rius, "Optimal Sizing of a Hybrid Grid-Connected Photovoltaic - Wind - Biomass Power System," Applied Energy, Vol. 154, No. 15, pp. 752-762, 2015

10. S. Nishikawa, "Optimum Ratio of PV Output Energy in Stand-Alone PV and WG Hybrid System," Transactions of the Institute of Electrical Engineers of Japan B A Publication of Power \& Energy Society, Vol. 120, No. 5, pp. 760-765, 2000

11. P. Karki, B. Adhikary, and K. Sherpa, "Comparative Study of Grid-Tied Photovoltaic (PV) System in Kathmandu and Berlin using PVsyst," in Proceedings of 2012 IEEE Third International Conference on Sustainabel Energy Technologies, pp. 196-199, 2012

12. A. Arjun, B. Vinod, N. Kumaresan, et al., "A Power Electronic Controller for PV-Tied Grid-Connected System with Single Parameter Sensing for Mppt using Boost Converter and Line-Commutated Inverter," in Proceedings of IEEE Third International Conference on Sustainable Energy Technologies, IEEE, pp. 36-40, 2012

13. J. Wang and F. Yang, "Optimal Capacity Allocation of Standalone Wind/Solar/Battery Hybrid Power System based on Improved Particle Swarm Optimisation Algorithm," IET Renewable Power Generation, Vol. 7, No. 5, pp. 443-448, 2013

14. R. Singh and R. Banerjee, "Estimation of Rooftop Solar Photovoltaic Potential of a City," Solar Energy, Vol. 115, 2015

15. M. C. Alonso-García, J. M. Ruiz, and F. Chenlo, "Experimental Study of Mismatch and Shading Effects in the I - V Characteristic of a Photovoltaic Module," Solar Energy Materials and Solar Cells, Vol. 90, No. 3, 2005

16. I. Yahyaoui, A. Atieh, and F. Tadeo, "Giuseppe Marco Tina. Energetic and Economic Sensitivity Analysis for Photovoltaic Water Pumping Systems,” Solar Energy, Vol. 144, 2017

17. M. Maltoni, A. Leggieri, G. Maggiotto, P. M. Congedo, and M. G. De Giorgi, "Long Term Performance, Losses and Efficiency Analysis of a 960 kWP Photovoltaic System in the Mediterranean Climate," Energy Conversion and Management, Vol. 145, 2017 